\title{
PDGF-AB rich-trombocyte lysate supplementation from breast cancer patients increased the proliferation of breast cancer stem cells
}

\author{
Wiwi A. Kartolo, ${ }^{1}$ Jeanne A. Pawitan, ${ }^{2,3}$ Alida R. Harahap, ${ }^{4}$ Septelia I. Wanandi ${ }^{5}$ \\ ${ }^{1}$ Faculty of Medicine, Universitas Indonesia, Jakarta, Indonesia \\ ${ }^{2}$ Department of Histology, Faculty of Medicine, Universitas Indonesia, Jakarta, Indonesia \\ ${ }^{3}$ Stem Cell Medical Technology Integrated Service Unit, Cipto Mangunkusumo Central Hospital-Faculty of Medicine, Universitas \\ Indonesia, Jakarta, Indonesia \\ ${ }^{4}$ Department of Clinical Pathology, Faculty of Medicine, Universitas Indonesia, Jakarta, Indonesia \\ ${ }^{5}$ Department of Biochemistry and Molecular Biology, Faculty of Medicine, Universitas Indonesia, Jakarta, Indonesia
}

\section{ABSTRACT}

Background: Thrombocytosis in breast cancer (BC) patient was thought to play a role in the invasiveness of breast cancer stem cells (BCSCs). Modification of tumor microenvironment was proposed to increase the efficacy of anticancer therapy. This study was aimed to analyze the effect of platelet lysate (PL) as well as its PDGF-AB content as a tumor microenvironment on (CD24\% CD44 ${ }^{+}$) BCSC proliferation.

Methods: This was an experimental study that treated culture of BCSCs with PL from breast cancer (BC) patients or healthy donors. Venous blood from all subjects were subjected to prior hematology test and then processed to obtain platelet rich plasma (PRP). Platelet counts in PRP were determined. PRP was processed to obtain PL. PDGF-AB contents in PL were measured. PL at concentrations of $0.01 \%(\mathrm{v} / \mathrm{v})$ was supplemented into DMEM-F12 medium and used for culturing BCSCs (CD24 $/$ CD44 $4^{+}$cells). After 48 hours, total cell count, population doubling time (PDT), and cell viability were calculated and their correlation with platelet count and PDGF-AB levels were analyzed.

Results: BC patients $(n=5)$ had higher platelet counts and PDGF-AB levels in PL compared to healthy donors $(n=15),(p=0.02)$. PL from BC patients could stimulate the proliferation of BCSCs higher than healthy donors $(\mathrm{p}<0.001)$ and showed lower PDT value $(\mathrm{p}=0.001)$. Cell proliferation and PDT showed strong correlation with PDGF-AB level. This observation suggests that PDGF-AB has a role on BCSCs proliferation. PL showed no effect on BCSCs viability.

Conclusion: Breast cancer patient platelet lysate stimulated BCSC proliferation.

Keywords: breast cancer stem cells, PDGF-AB, platelet lysate, proliferation, PRP

pISSN: 0853-1773• eISSN: 2252-8083 • https://doi.org/10.13181/mji.v27i1.1596• Med J Indones. 2018;27:19-25

- Received 04 Jan 2016 • Accepted 24 Jan 2018

Corresponding author: Septelia I. Wanandi

septelia.inawati@ui.ac.id; septelia@gmail.com

Copyright @ 2018 Authors. This is an open access article distributed under the terms of the Creative Commons Attribution-NonCommercial 4.0 International License (http://creativecommons.org/licenses/by-nc/4.0/), which permits unrestricted non-commercial use, distribution, and reproduction in any medium, provided the original author and source are properly cited. 
Breast cancer (BC) has been one of the major health issues worldwide, including in Indonesia. The incidence, relapse, and mortality rate of $\mathrm{BC}$ is considered high and tend to increase from year to year. ${ }^{1}$ Cancer stem cells (CSCs) are associated with the relapse of the cancer. A cross-talk between CSCs that induces platelet activation and platelet-secreted growth factors that stimulate cancer cell growth has been described. ${ }^{2,3}$ Actively promoting cell growth, platelet rich plasma (PRP) has been widely used in clinical therapy for improving stem cell function in treatment for osteoarthritis ${ }^{1}$ and for autologous breast fat graft. ${ }^{4-6}$

CSCs are a subpopulation of cancer cells that own glycoprotein surface markers, which differ to those in ordinary cancer cells. Breast CSCs (BCSCs) could be identified based on the high expression of CD44 marker and the negative expression of CD24 (CD24/CD44+). CSCs have self-renewal abilit and pluripotency, which cause tumor initiation and are responsible to therapy resistance and cancer relapse. ${ }^{2}$ It has been reported that CSC growth and differentiation are influenced by the cell microenvironment. ${ }^{7,8}$ Cell microenvironment in the breast tissue consists of stromal cells (e.g., mesenchymal stem cells, endothelial cells, fibroblast, myofibroblast, immune cells and platelets) and extracellular matrix, which contains cytokines and growth factors (GFs) including platelet-derived growth factor (PDGF). ${ }^{7}$ PDGF was mitogenic and contributes to cell proliferation. ${ }^{9}$

Nowadays most of cancer therapy has been focusing on the inhibition of proliferation pathway as well as apoptosis induction of cancer cells. On the contrary, very rare treatment targets the microenvironment in cancer. ${ }^{10}$ PRP has been used in in vitro study to substitute fetal bovine serum (FBS) to grow and to support the differentiation of stem cells, due to having various growth factors including PDGF-AB. ${ }^{11}$ The PDGF-AB, a heterodimeric PDGF isoform assembled from both $A$ and $B$ subunits, is the second most abundant growth factor in PRP, after transforming growth factor $\beta 1$ (TGF $\beta 1$ ) whose effects are widely known. ${ }^{12}$ PDGF-AB is related to invasive and metastatic properties of breast cancer and has a mitogenic effect on cells and has been reported to be over activated in cancer patients, due to mutation. ${ }^{13}$ However, so far PRP as a modifier of microenvironment, especially PDGF-AB has not been tested in BCSCs.

Platelets counts as well as platelet lysates and their GF levels from BC patients were found to be different compared to those from healthy donors. ${ }^{14}$ Therefore, the aim of this study was to analyze the role of platelet lysates as tumor microenvironment from breast cancer patients compared to healthy donors, as well as its PDGF$\mathrm{AB}$ content on (CD24/CD44+) BCSC proliferation, population doubling time (PDT), and viability.

\section{METHODS}

This experimental study was approved by Ethical Committee from Universitas Indonesia with ethical clearance No. 764/UD.F1/ ETIK/2014. Study was done from April 2014 to February 2016 at Molecular Biology Laboratory, Department of Biochemistry and Molecular Biology, Faculty of Medicine Universitas Indonesia (FMUI); Laboratorium Terpadu FMUI; and Eijkman Laboratory.

Female subjects, aged 20-45 years, with body mass index $18.5-30 \mathrm{~kg} / \mathrm{m}^{2}$, having no malignancy history, nor reported pain in any area, fever, abnormal bleeding, tumor finding, lymph node swelling, skin retraction, skin abnormal appearance and having no antiplatelet medication within one week before blood collection, were included in this study as healthy donors. BC patients from Dharmais Hospital National Cancer Center Jakarta with different histopathology, including invasive lobular carcinoma, invasive carcinoma of no special type and metaplastic carcinoma were recruited in this study. BC patients receiving chemotherapy, radiotherapy, and transfusion within 3 months before blood collection were excluded. Prior to blood collection, all subjects were informed and agreed to sign the informed consent form.

Blood from each donor would be subjected to complete blood count (CBC) test and PRP preparation. PRP then was freezedthawed twice and centrifuged to obtain platelet lysate. Platelet lysate was added to the CD24\% CD $44^{+}$BCSCs culture to test its effect to the BCSCs proliferation. 
Breast cancer stem cells (CD24\%) $\mathrm{CD}_{4}{ }^{+}$) were generated from previous studies at the Biochemistry and Molecular Biology Laboratory, the primary cultures of human breast cancer cells that have been sorted with magnetic beads (MACS) conjugated with anti-CD24 and anti-CD44 antibodies resulting in cell fractions CD24 $/ \mathrm{CD}^{-} 4^{+}$and CD24/CD44- cells. The patent application for the primary and stem cell method of human breast cancer CD24/CD44+ cells has been registered with the Directorate General of Intellectual Property Rights of the Ministry of Justice and Human Rights (No. P0021300369).

\section{Complete blood count test}

Twelve $\mathrm{ml}$ of collected whole blood from each donor was placed into EDTA tubes and all were homogenized. Within 6 hours after collection, $500 \mu \mathrm{l}$ of whole blood was used for CBC test using Sysmex poCH_1001 and the rest was used for PRP preparation

\section{PRP, platelet lysate preparation and PDGF-AB assay}

PRP was prepared from whole blood using the modified soft spin centrifugation method. The optimal centrifugation was done at 1,600 rpm for 5 minutes at room temperature. After centrifugation, all plasma was collected from each donor and called as PRP. PRP was then directly subjected to platelet count assay. All the rest of PRP were then stored in $-20{ }^{\circ} \mathrm{C}$ for further assay.

Before running the assay, PRP from all donors were freezes-thawed twice in $-80{ }^{\circ} \mathrm{C}$. Then, PRP was centrifuged at $1,000 \mathrm{rpm}$ for 5 minutes at room temperature. The supernatant was collected and labeled as platelet lysate.

The level of PDGF-AB in the platelet lysate was measured using human PDGF-AB ELISA KIT® (Cat. No. Ab100623, Abcam, Cambridge, United Kingdom) and presented in ng per $\mathrm{mL}$ platelet lysate and per platelet lysate total protein.

\section{Supplementation of platelet lysate to culture medium}

Platelet lysates from both BC patients and healthy donors were added into CD24\% $\mathrm{CD}_{4} 4^{+} \mathrm{BCSC}$ culture medium. The BCSCs highly express Oct4 and ALDH mRNA, and able to form mammospheres in in vitro culture. CD24 $/ \mathrm{CD}^{-} 4^{+}$
BCSCs without platelet lysate supplementation were used as control group.

DMEM-F12 culture medium was mixed with amphotericin B 1\%, penicillin-streptomycin $1 \%$, glutamax $1 \%$, heparin $1 \%$, without FBS supplementation (Gibco, Ltd. Singapura). This complete culture medium was filtered using $0.2 \mu \mathrm{m}$ syringe filter. Platelet lysate from either healthy donors or breast cancer patients were added into complete culture medium to give a platelet lysate final concentration of $0.01 \%$ $\mathrm{v} / \mathrm{v}$. This medium was then filtered using 0.2 $\mu \mathrm{m}$ syringe filter. CD24 $/$ CD44 ${ }^{+}$BCSCs $(150.000$ cells/well) were seeded and incubated in $2 \mathrm{~mL}$ platelet lysate supplemented medium for 48 hours. After 48 hours, cells were harvested and counted using $0.4 \%$ Trypan blue solution. Cell counting (viable, dead, and total cells) was done using LUNA ${ }^{\mathrm{TM}}$ Automatic Cell Counter, according to manufacturer's protocol. Then, the viability and PDT value were calculated using formula:

$$
\begin{aligned}
& \text { Cell viability }(\%)=\frac{\text { viable cell }}{\text { viable }+ \text { dead cells }} \times 100 \% \\
& \text { PDT }(\text { days })=\frac{\log 2 \times \Delta t}{\log (\mathrm{NH})-\log (\mathrm{NI})}
\end{aligned}
$$

$\Delta \mathrm{t}$ is the time from seeding to harvesting (2 days), $\mathrm{NH}$ is harvested cell number, NI is seeded cell number. Total cell count, PDT, and cell viability were normalized to control untreated with platelet lysates.

The whole data e.g., platelet number (cell/ $\mu \mathrm{L}$ ) in the whole blood and in the PRP before freezing-thawing, as well as level of PDGF-AB (pg/ $\mu \mathrm{g}$ of total protein) found in platelet lysate from $B C$ patients and healthy donors, as well as total cell count, PDT (day), and viability of CD24-CD44+ BCSCs from three groups (cells supplemented with BC patients' and healthy donors' platelet lysates and control) were compared and analyzed using Statistical Analysis Software Package 23.0 version. Normality test was done using SaphiroWilk test. Non-normally distributed data were first transformed to logarithmic data. Normally distributed data were analyzed using independent t-test, while non-normally distributed data was analyzed using Mann-Whitney test. Mean difference was considered significant if $\mathrm{p}<0.05$. 
Total cell count, PDT value, and cell viability were subjected to Pearson correlation test for normally distributed data and Spearman's rho correlation test for non-normally distributed data to see their correlation with platelet count in PRP as well as level of PDGF-AB in platelet lysates (ng/mL).

\section{RESULTS}

Blood profile from $5 \mathrm{BC}$ patients and 15 healthy donors were within normal range. Generally, there was no significant difference in whole blood profile (red blood cell, white blood cell, and platelet counts, as well as hemoglobin and hematocrit content) between the two groups (Table 1).

Following the PRP preparation using soft spin centrifugation, platelet count obtained from BC patients were higher than healthy donors (Table 1). PDGF-AB levels in $\mathrm{BC}$ patients' platelet lysates were significantly higher than those from healthy donors (Table 1). Furthermore, PDGF-AB level was strongly correlated with platelet count in PRP $(r=0.86$, $\mathrm{p}<0.001$; Spearman's rho correlation).

CD24-CD44 ${ }^{+}$BCSCs cultured in DMEM-F12 culture medium without FBS and treated with $0.01 \%$ platelet lysate from breast cancer patients were more confluent compared to those from healthy donors and control group (Figure 1). This condition was confirmed with total cell count result in \% ratio to control that showed significant higher number of BCSCs in BC patients group than healthy donors (Figure 2). This indicates higher BCSCs proliferation rate in BC patients group and it was confirmed by PDT result which were lower in BC patients group (Figure 3). No significant morphological difference was observed between cells from the three groups. Viability cell result in $\%$ ratio to control in all groups (supplemented

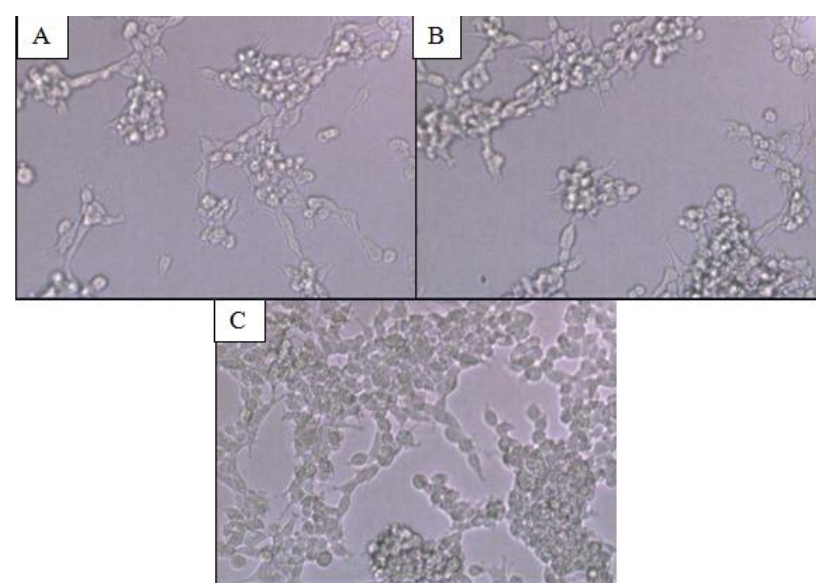

Figure 1. CD24-/CD44+ BCSCs Culture (A) Cells without platelet lysate supplementation (control group); (B) cells supplemented with platelet lysates from healthy donors; (C) cells supplemented with platelet lysates from breast cancer patients. Magnification 10 times under inverted microscope. Cells (A), (B), and (C) showed similar morphology. Cells in (C) were more confluent compared to cells in (A) and (B). $\mathrm{BCSC}=$ Breast cancer stem cells

Table 1. Whole blood, platelet rich plasma, and platelet lysate analysis

\begin{tabular}{|c|c|c|c|}
\hline \multirow{2}{*}{ Parameter } & \multicolumn{2}{|c|}{ Result (Mean \pm SD) } & \multirow{2}{*}{$\mathrm{p}$} \\
\hline & Healthy Donors & Breast Cancer Patients & \\
\hline \multicolumn{4}{|l|}{ Whole Blood } \\
\hline Red blood cell $\left(\mathrm{x} 10^{6}\right.$ cells $\left./ \mu \mathrm{l}\right)$ & $4.78 \pm 0.45$ & $4.76 \pm 0.46$ & $0.95^{*}$ \\
\hline White blood cell $\left(\mathrm{x} 10^{3}\right.$ cells $\left./ \mu \mathrm{l}\right)$ & $7.84 \pm 1.90$ & $8.48 \pm 1.87$ & $0.52^{*}$ \\
\hline Hemoglobin (g/dl) & $12.02 \pm 1.40$ & $13.00 \pm 0.86$ & $0.16^{*}$ \\
\hline Hematocrit (\%) & $38.39 \pm 3.14$ & $40.68 \pm 2.35$ & $0.15^{*}$ \\
\hline Platelet count $\left(\mathrm{x} 10^{3}\right.$ cells $\left./ \mu \mathrm{l}\right)$ & $294.33 \pm 78.86$ & $347.20 \pm 39.06$ & $0.17^{*}$ \\
\hline \multicolumn{4}{|l|}{ PRP } \\
\hline Platelet count $\left(\mathrm{x} 10^{3}\right.$ cells $\left./ \mu \mathrm{l}\right)$ & $324.27 \pm 101.73$ & $461.00 \pm 87.54$ & $0.02^{\dagger}$ \\
\hline \multicolumn{4}{|l|}{ Platelet lysate } \\
\hline Level of PDGF-AB (pg/ $\mu$ g total protein) & $0.32 \pm 0.08$ & $0.43 \pm 0.09$ & $\mathbf{0 . 0 2}^{*}$ \\
\hline
\end{tabular}

$\mathrm{PRP}=$ platelet rich plasma; $\mathrm{PDGF}-\mathrm{AB}=$ platelet derived growth factor- $\mathrm{AB} ;{ }^{*}=$ independent $\mathrm{t}$-test; $\dagger=$ independent $\mathrm{t}$-test (natural $\log$ transformed data) 
by $\mathrm{BC}$ patient or healthy donor platelet lysate) had almost similar cell viability with median was around 97-99\% (Figure 4).

Total cell count and PDT in \% ratio to control showed moderate correlation, but insignificant with platelet count in PRP. This fact might be due to the fact that not all platelets were

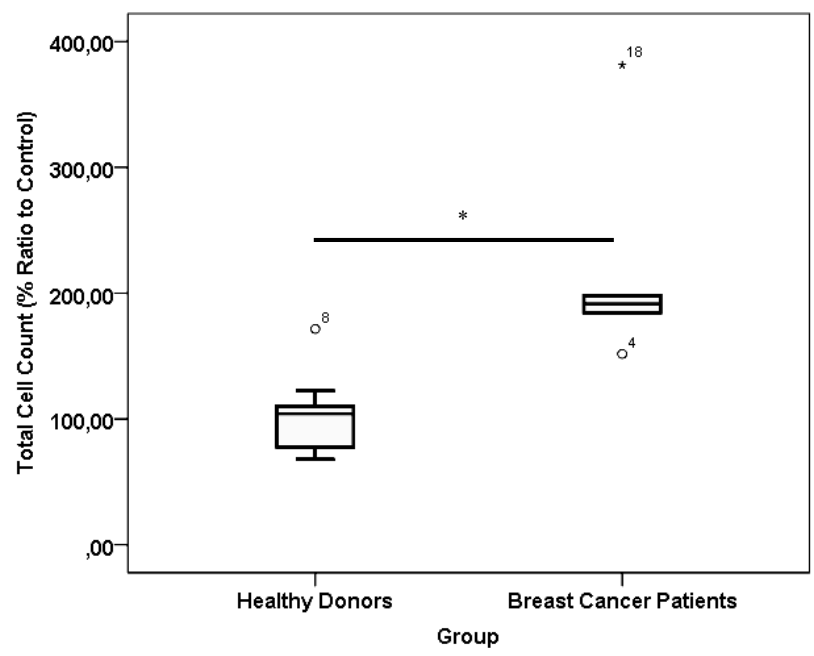

Figure 2. ${ }^{*}$ ) $p<0.001$, Mann-Whitney test. Total cell count of healthy donor and breast cancer patient platelet lysate supplementation group. Number of samples was 20. Median from healthy donors group was $104.18 \%$ (25th-75th percentiles, $76.49-110.36 \%$ ) and from breast cancer patients group was $191.29 \%$ (25th-75th percentiles, $176.16-243.88 \%$ )

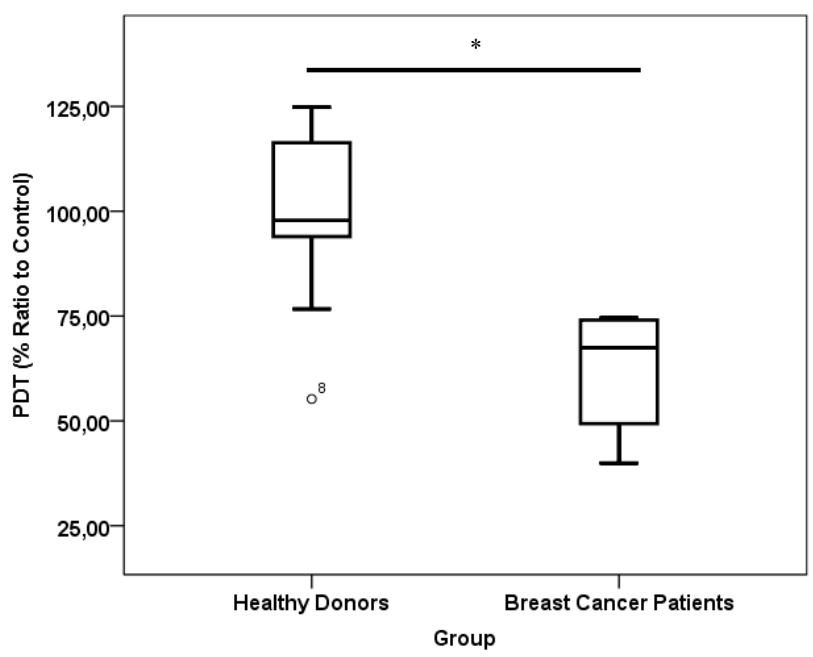

Figure 3. Population doubling time value of cells in healthy donor and breast cancer patient platelet lysate supplementation group. Number of samples was 20. Mean from healthy donors group was $100.46 \pm 19.01 \%$ and from breast cancer patients group was $62.13 \pm 14.46 \%$. PDT= population doubling time lysed and secreted their contents upon freeze thaw (data not shown). Total cell count showed strong correlation with PDGF-AB level in platelet

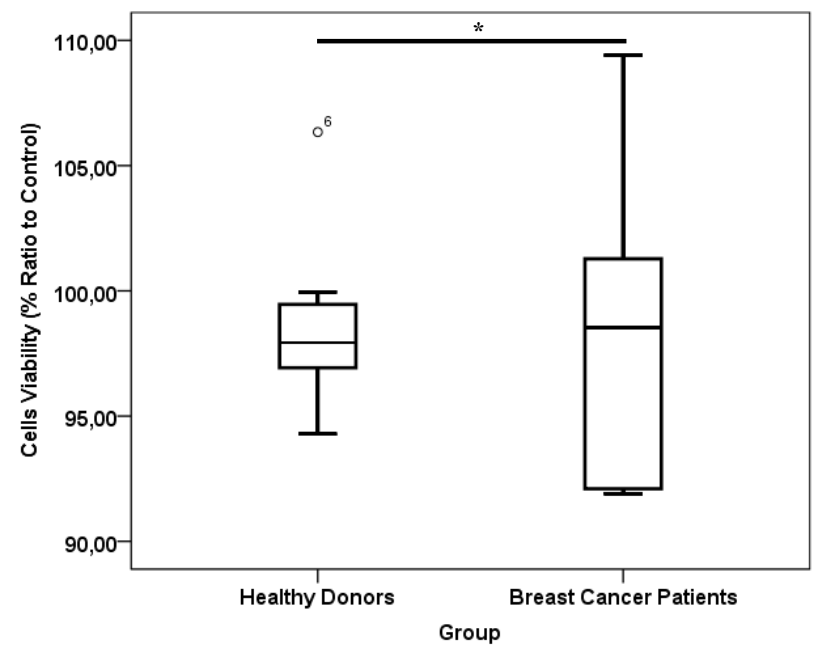

Figure 4. $\left.{ }^{*}\right) \mathrm{p}=0.87$, Mann-Whitney test viability of cells in healthy donor and breast cancer patient platelet lysate supplementation group. Number of samples was 20. Median for healthy donors group was $97.93 \%$ (25th-75th per-centiles, $96.87-96.55 \%)$ and from breast cancer patients group was 98.54\% (25th-75th percentiles, 92.0-103.31\%)

Table 2. Correlation between total cell count, PDT value and cell viability with platelet count in PRP and PDGF-AB level per ml platelet lysate

$\begin{array}{cc}\begin{array}{c}\text { Platelet count in } \\ \text { PRP }\end{array} & \begin{array}{c}\text { PDGF-AB level } \\ \text { per ml platelet } \\ \left(10^{3} \text { cells } / \mu \mathrm{l}\right)\end{array} \\ \begin{array}{c}\text { lysate } \\ (\mathrm{ng} / \mathrm{ml})\end{array}\end{array}$

Total cell count $(\%$ ratio to control)

\begin{tabular}{|ccc|}
\hline Correlation & $0.38(\mathrm{~b})^{\dagger}$ & $0.52(\mathrm{~b})^{\ddagger}$ \\
\hline $\mathrm{p}$ value & 0.09 & 0.02 \\
$\mathrm{~N}$ & 20 & 20 \\
\hline PDT $(\%$ ratio of control $)$ & & \\
\hline Correlation & $-0.45(\mathrm{a})^{\dagger}$ & $-0.57(\mathrm{~b})^{\ddagger}$ \\
\hline p value & 0.05 & 0.01 \\
$\mathrm{~N}$ & 20 & 20 \\
\hline
\end{tabular}

Cells viability (\% ratio to control)

\begin{tabular}{lcc} 
Correlation & $0.24(\mathrm{~b})^{*}$ & $0.18(\mathrm{~b})^{*}$ \\
\hline $\mathrm{p}$ value & 0.30 & 0.45 \\
$\mathrm{~N}$ & 20 & 20 \\
\hline
\end{tabular}

$\mathrm{a}=$ Pearson correlation; $\mathrm{b}=$ Spearman's rho correlation; *= very weak correlation $(\mathrm{r}=0-0.25) ;{ }^{\dagger}=$ moderate correlation $(\mathrm{r}=0.26-0.50) ;=$ strong correlation $(\mathrm{r}=0.51-0.75)$. $\mathrm{PDT}=$ population doubling time 
lysates $(\mathrm{ng} / \mathrm{mL})$. This data was in line with PDT value of cells that was negatively correlated with PDGF-AB level in platelet lysates. In contrast, correlation observed between cell viability and PDGF-AB levels in platelet lysates was considered negligible (Table 2). Platelet lysates or PDGF-AB particularly affected BCSC proliferation, but not $\mathrm{BCSC}$ viability, as they are non-toxic.

\section{DISCUSSION}

The role of platelet in cancer metastasis has been previously described. ${ }^{3}$ Cancer cells activate platelet and amplify platelet aggregation by increasing expression of surface integrins, selectins and secretion of granules. After activated, the platelet becomes degranulated and secretes various growth factors, which in turn stimulates cancer cell growth. ${ }^{3}$ Cross-talk between platelets and cancer cells results in increased platelet production. It was clearly seen in the higher platelet count found in whole blood of BC patients than healthy donors found in this study.

Platelets induce cancer cell growth by releasing growth factors, including PDGF. ${ }^{11}$ The activation of PDGF signaling pathway will activate Ras/ extracellular-signal-regulated kinase (ERK) cell proliferation pathway. ${ }^{16}$ This signaling pathway was reported to be frequently activated in breast cancer. Furthermore, PDGF was over expressed in cancer patients due to point mutation in PDGF and PDGF receptor gene. ${ }^{17,18}$ This study showed higher platelet counts in $\mathrm{BC}$ patients that might cause higher PDGF-AB levels, and thus the activation of PDGF signaling pathway. The PDGF signaling pathway will activate Ras/extracellular signalregulated kinase (Ras/ERK). ERK is a subfamily of mitogen-activated protein kinases (MAPKs), which is involved in regulation of various cellular responses, namely cell proliferation, differentiation and apoptosis. ${ }^{19,20}$ In this study, we did not elaborate further on the signaling pathways, which is a limitation to this study.

Normal stem cells required nutrition to grow. ${ }^{21}$ On the other hand, CSCs can survive and live in conditions with limited nutrition. It was proven by the fact that CD24-CD $44^{+}$BSCSs still survived and proliferated in control group. As expected, platelet lysate supplementation increased BCSCs proliferation. The role of PDGF-
$\mathrm{AB}$ in BCSCs proliferation was confirmed by higher number of BCSCs and lower PDT from $\mathrm{BC}$ platelet lysate group with strong correlation observed between number of BCSCs and PDT with PDGF-AB level.

However, other study using endothelial cells (ECs) found that PDGF-BB neutralization did not significantly changed endothelial cell proliferation. Though PDGF-BB concentration in PRP was quite high, but might be not high enough to stimulate cell proliferation. In the same study, EGF neutralization attenuated cell proliferation, although EGF concentration in PRP was only less than $2 \%$ of PDGF-BB concentration. It should be noted that to be able to stimulate proliferation, the GF concentration added to cells should exceed its effective concentration. ${ }^{21}$ In that case, PDGF-AB might not act alone but was acting synergistically with EGF or other GFs to stimulate ECs proliferation, which was different with our study. It is plausible since unlike normal cells such as ECs, BCSCs less depend on nutrition for their proliferation.

Effect of platelet lysates in BCSC proliferation was confirmed by the result of PDT. To analyze whether platelet lysates affected BCSC death, we analyzed BCSC viability after treatment. This study showed that platelet lysate supplementation induced BCSC proliferation but did not affect cell viability. However, this result only applied in BCSC culture that might be different if other cancer cell line were used. Overactivation of PDGF were reported in several cancer cell types, ${ }^{17}$ and this study showed higher PDGF-AB levels in $\mathrm{BC}$ patients. It also been reported that PDGF-AB in physiological concentration was mitogenic for other cancer cell type, like SaOS-2 osteoblasts, an osteosarcoma derived cell line, thus targeting PDGF signaling pathway would be potential for various cancer treatment. It is generally known that PDT only represents the time that cells need to get doubled in number, but the time when cells begin to proliferate remain unidentified. Thus, we suggest performing cell cycle assays for further analysis.

Platelet counts (cells/ $\mu \mathrm{l}$ ) showed no significant difference between blood samples from healthy donors and breast cancer patients, but there was significant difference in the PRP (Table 1). The reason for this discrepancy might be due to the higher platelet count and hematocrite in breast cancer patients. Higher hematocrite 
caused lower amount of plasma, and the higher platelet count in blood though insignificant might become significant in PRP due to the reduces volume of PRP.

This study only addressed the roles of platelet lysate and PDGF-AB on BCSC proliferation, PDT and viability, but did not studied its invasive and metastatic properties, which is a limitation of this study. Moreover, PRP contains many other growth factors which were not address in this study. A comprehensive study of PRP-contained factors that caused deleterious effect may benefit for higher effectiveness in breast cancer treatment, in term of counteracting proliferation, invasive and metastatic properties of BSCSs.

In conclusion, supplementation of platelet lysates from breast cancer patients to breast cancer stem cell culture medium stimulated BCSC proliferation, due to their higher PDGF-AB content compared to those from healthy donors.

\section{Conflicts of interest}

Jeanne A. Pawitan is one of the editorial board members, but was not involved in the review or decision process of the article.

\section{Acknowledgment}

This study was funded by Hibah PITTA 2017 from Direktorat Riset dan Pengabdian Masyarakat Universitas Indonesia (DRPM-UI). The authors would like to send special gratitude to Dr. Ika Yustisia, Dr. Purnamawati, and Resda A. Syahrani, M.Biomed for their excellent assistance in preparing BCSC culture.

\section{REFERENCES}

1. GLOBOCAN [Internet]. Estimated cander incidence, mortality and prevalence worldwide in 2012 [cited 2016 March 1]. Available from: http://globocan.iarc.fr/ Default.aspx.

2. Klevebring F, Rosin G, Ma R, Lindberg J, Czene K, Kere J, et al. Sequencing of breast cancer stem cell populations indicates a dynamic conversion between differentiation states in vivo. Breast Cancer Res. 2014;15(R72).

3. Tesfamariam B. Involvement of platelets in tumor cell metastasis. Pharmacol Ther. 2016; 157:112-9.

4. Van Pham P, Bui KH, Ngo DQ Vu NB, Truong NH, Phan NL, et al. Activated platelet-rich plasma improves adiposederived stem cell transplantation efficiency in injured articular cartilage. Stem Cell Res Ther. 2013;4(4):91.
5. Jin R, Zhang L, Zhang Y-G. Does platelet-rich plasma enhance the survival of grafted fat? An update review. Int J Clin Exp Med. 2013;6(4):252-8.

6. Foster TE, Puskas BL, Mandelbaum BR, Gerhardt MB, Rodeo SA. Platelet-rich plasma from basic science to clinical applications. Am J Sports Med. 2009;37(11):2259-72.

7. Kanojia D, Chen H. The Microenvironment of Breast Cancer Stem Cells. In: Gunduz M, Gunduz E, editors. Breast cancer - focusing tumor microenvironment, stem cells and metastasis. Rijeka: InTech; 2011. p. 237-46.

8. Korkaya H, Liu S, Wicha MS. Breast cancer stem cells, cytokine networks, and tumor microenvironment. J Clin Invest. 2011;121(10):3804-9.

9. De Donatis A, Comito G, Burricchi F, Vinci M, Parenti A, Caselli A, et al. Proliferation Versus Migration in Platelet-Derived Growth Factor Signaling. J Biol Chem. 2008;283(29):19948-56.

10. Swartz M, Iida N, Roberts E, Sangaletti S, Wong M, Yull F. Tumor microenvironment complexity: emerging roles in cancer therapy. Cancer Res. 2012;27:2473-80.

11. Sari P, Luviah E, Nugraha Y, Pawitan JA, Lilianty J, Purwoko RY. Various growth factor yields in various platelet rich plasma processing methods. BTAIJ. 2014;9(11): 475-8.

12. Chao YL, Shepard C, Wells A. Breast carcinoma cells reexpress E-cadherin during mesenchymal to epithelial reverting transition. Mol Cancer. 2010;9:179.

13. Colciago A, Celotti F, Casati L, Giancola R, Castano S, Antonini G, et al. In vitro effects of PDGF Isoforms (AA, $\mathrm{BB}, \mathrm{AB}$ and $\mathrm{CC}$ ) on migration and proliferation of SaOS-2 osteoblasts and on migration of human osteoblasts. Int J Biomed Sci. 2009;5(4):380-9.

14. Sierko E, Wojtukiewicz M. Platelets and angiogenesis in malignancy. Semim Thromb Hemost. 2004;30:95108.

15. McCubrey JA, Steelman LS, Chappell WH, Abrams SL, Wong EW, Chang F, et al. Roles of the Raf/MEK/Erk pathway in cell growth, malignant transformation and drug resistance. Biochim Biophys Acta. 2007;1773(8):1263-84.

16. Heldin C-H. Targeting the PDGF signaling pathway in tumor treatment. Cell Comm Signal. 2013;11:97.

17. Carvalho I, Milanezi F, Martins A, Reis RM, Schmitt F. Overexpression of platelet-derived growth factor receptor $\alpha$ in breast cancer is associated with tumour progression. Breast Cancer Res. 2005;7(5):R788-95.

18. Cross TG, Scheel-Toelner D, Henriquez N, Deacon E, Salmon M, Lord J. Serine/threonine protein kinases andapoptosis. Exp Cell Res. 2000;256:34-41.

19. Pearson G, Robinson F, Beers Gibson T, Xu B. Mitogen-activated protein (MAP) kinase pathways: regulation and physiological functions. Endocr Rev. 2001;22(2):153-83.

20. Suryani D, Pawitan JA, Lilianty J, Purwoko RY, Liem IK, Damayanti L. Comparison of fetal bovine serum and platelet-rich plasma on human lipoaspirate-derived mesenchymal stem cell proliferation. Med J Indones. 2013;22;146-51.

21. Bertrand-Duchesne M-P, Grenier D, Gagnon G. Epidermal growth factor released from platelet-rich plasma promotes endothelial cell proliferation in vitro. J Periodontal Res. 2010;45(1):87-93. 